\title{
Schnelle Auswertung von Beschichtungsvorgängen
}

\author{
Mit einem neuen Messgerät lassen sich Schichtdicken auf dünnwandigen Bauteilen präzise und \\ einfach messen. Die sofortige Dokumentation der Messergebnisse spart zudem Zeit und Geld.
}

Das neue Schichtdickenmessgerät Elcometer 415 für die Farb- und Pulverindustrie ermöglicht eine einfache, schnelle und genaue Schichtdickenmessung an glatten und dünnwandigen Bauteilen. Es erkennt selbstständig Eisen- und Nichteisenmetalle und schaltet automatisch zwischen den jeweils dafür benötigten Messverfahren um.

Konzipiert ist das Gerät für die Messung von ausgehärteten Farb- und Pulverbe- schichtungen bis zu $1000 \mu \mathrm{m}$. Die EinPunkt-Kalibrierung und Nullung garantieren eine sehr hohe Genauigkeit auf glatten und dünnen Substraten. Mit einer Messgeschwindigkeit von mehr als 60 Messwerten pro Minute ermöglicht das Gerät eine schnelle Erfassung der Werte. Dies reduziert die Inspektionszeit und erhöht die Produktivität.

Das Schichtdickenmessgerät ist einfach zu handhaben und die automatische Dre-

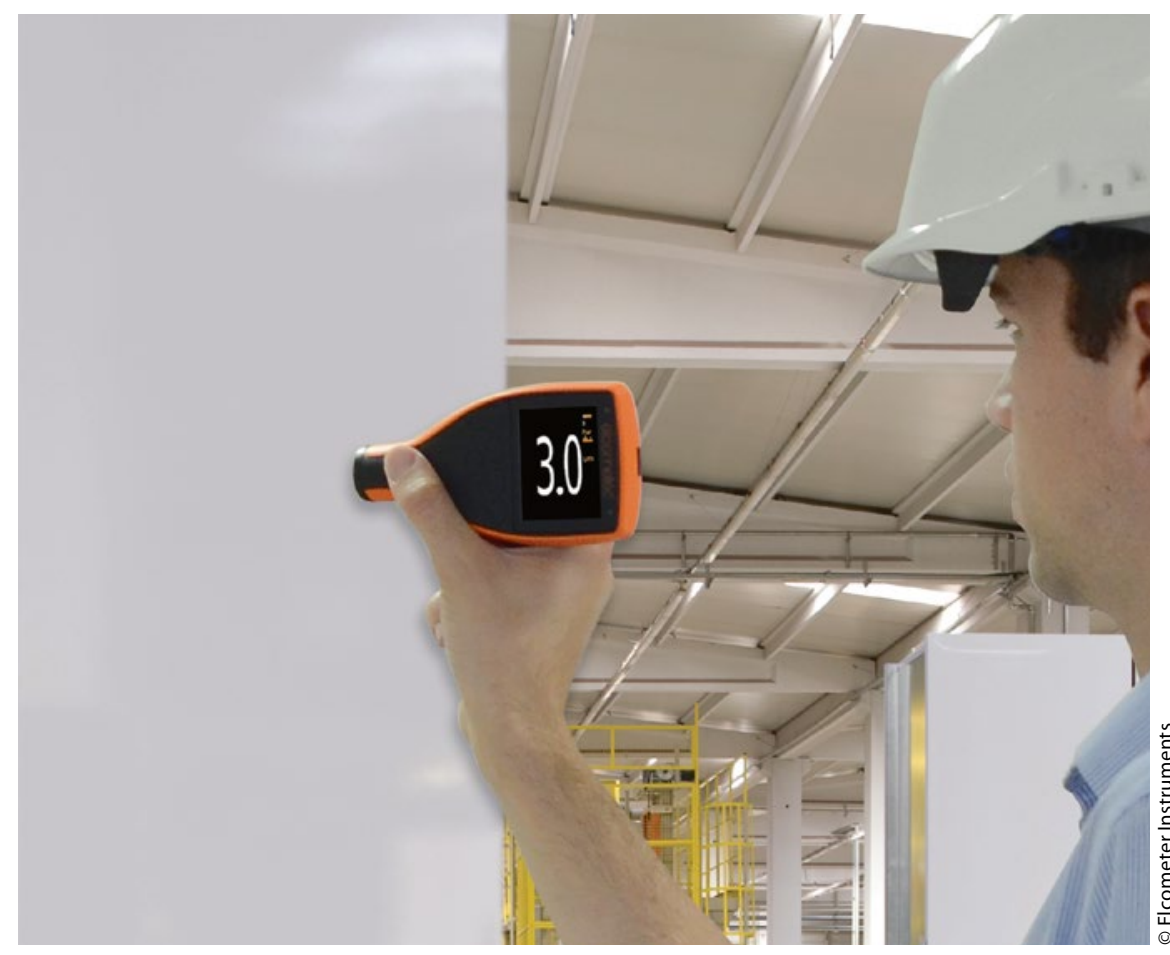

Das neue Schichtdickenmessgerät ermöglicht eine einfache, schnelle und genaue Schichtdickenmessung an glatten und dünnwandigen Bauteilen.

hung des Farbdisplays sorgt für eine klare Sicht bei jedem Messwinkel. Durch die Verwendung von Bild-Symbolen lässt sich das Gerät sehr leicht kalibrieren. Außerdem ist es robust und pulverbeständig entsprechend der Schutzklasse IP64.

Neben der Beschichtungsdicke werden auch die statistischen Werte für die Beurteilung des generellen Zustands der Beschichtung angezeigt: Die Anzahl der Messwerte (n), die durchschnittliche (x) Schichtdicke, die geringste (Lo) und die höchste Schichtdicke (Hi).

Alle Messwerte können zur umgehenden Berichterstellung über Bluetooth oder USB an die ElcoMaster Software im PC übertragen werden. Über die Bluetooth-Schnittstelle ist es ebenfalls möglich, die Messwerte auf ein Smartphone oder Tablet zu übertragen. Im App Store ist die Software kostenfrei verfügbar. Damit kann innerhalb von 30 Sekunden ein fertiger Bericht erstellt werden und man erhält sofort eine statistische und grafische Auswertung des Beschichtungsvorganges. In den Bericht lassen sich Bemerkungen, Notizen oder Bilder einfügen. Auch Grenzwerte können nachträglich gesetzt werden. //

\section{Kontakt \\ Elcometer Instruments GmbH \\ Aalen}

Tel. 07361528060

de_info@elcometer.de

www.elcometer.de 